\title{
PENGARUH CUSTOMER RELATIONSHIP MANAGEMENT TERHADAP LOYALITAS PELANGGAN INDOSAT BENGKULU
}

\author{
Ade Tiara Yulinda \\ Fakultas Ekonomi Universitas Muhammadiyah Bengkulu \\ Ade91tiarayulinda@gmail.com
}

\begin{abstract}
ABSTRAK
Ade Tiara Yulinda: Tujuan dari penelitian ini adalah untuk menganalisis pengaruh manajemen hubungan pelanggan (teknologi, orang, proses dan pengetahuan) terhadap loyalitas pelanggan pada PT. Indosat Bengkulu. Dengan menggunakan penelitian survei, teknik analisis menggunakan skala likert dan menggunakan analisis regresi linier berganda. Sampel yang digunakan adalah 100 responden. Hasil penelitian ini dapat disimpulkan bahwa manajemen hubungan pelanggan dalam variabel teknologi, orang, proses, pengetahuan mempengaruhi loyalitas terhadap perusahaan, dan sebagian pengetahuan mempengaruhi loyalitas pelanggan, sedangkan terhadap teknologi, masyarakat, Proses tidak mempengaruhi loyalitas pelanggan secara signifikan.
\end{abstract}

\section{ABSTRACT}

Ade Tiara Yulinda: The objectives of this research is to analyze the influence of customer relationship management (technology, people, process and knowledge) on customer's loyalty at PT. Indosat Bengkulu. Using survey research, analysis techniques using a likert scale and using multiple linear regression analysis. Samples used were 100 respondents. The result of this research, can be concluded that the customer relationship management in the variable of technology, people, process, knowledge influenced the loyalty to the company, and partially the knowledge influenced the loyalty of the customers, while toward the technology, people, process didn't influence the loyalty of the customers significantly.

Key Words : Customer Relationship Management, Technology, People, Process, Knowledge.

\section{PENDAHULUAN}

Perkembangan bisnis saat ini semakin meningkat dengan pesat. Dalam perkembangan bisnis sekarang perusahaan dihadapkan pada suatu kenyataan adanya persaingan yang semakin tajam. Situasi ini, akan menimbulkan masalah-masalah pemasaran yang semakin lama semakin kompleks. Sukses atau tidaknya perusahaan seringkali tergantung pada kemampuan perusahaan dalam penguasaan strategi pemasarannya. Perusahaan saat ini juga semakin kreatif dan inovatif dalam menarik pelanggan dengan memberikan berbagai fasilitas pelayanan modern.

Situasi ini, akan menimbulkan kompleksitas dalam aktivitas pemasaran. Sukses atau tidaknya perusahaan seringkali tergantung pada kemampuan perusahaan dalam penguasaan strategi pemasarannya. Perusahaan berlomba-lomba menemukan cara bagaimana memenangkan persaingan dengan strategi perusahaan tersendiri. Melihat kondisi ini pelaku bisnis memikirkan bagaimana cara agar usaha dalam bisnis dapat memperoleh keuntungan dengan cara menambah pelanggan baru dan mempertahankan pelanggan yang lama.

Upaya yang dilakukan perusahaan tersebut merupakan agenda yang harus memperoleh perhatian untuk menciptakan loyalitas pelanggan. Loyalitas pelanggan terjadi kerena pelanggan merasa puas atas kualitas pelayanan yang diberikan dengan baik. Kualitas pelayanan mempunyai pengaruh yang signifikan terhadap loyalitas pelanggan. Loyalitas pelanggan dapat dipertahankan dengan mengembangkan hubungan dan kesetiaan yang lebih kuat dengan para pelanggan (Kotler, 2008). Untuk menciptakan kepuasaan pelanggan, maka perusahaan-perusahaan yang bergerak dibidang jasa pelayanan masyarakat harus menciptakan dan mengolah suatu sistem untuk memperoleh pelanggan yang lebih banyak dan juga memiliki kemampuan untuk mempertahankan pelanggan setia. Menurut Alfansi (2010), Dalam industri yang kompetitif dan pasar yang dewasa, CRM merupakan strategi penting untuk mempertahankan pelanggan.

Di Indonesia perusahaan yang bergerak di bidang jasa sudah semakin banyak. Banyaknya perusahaan yang bermunculan dari berbagai provider baru yang akan berdampak semakin ketatnya persaingan bisnis, terutama dalam menarik pelanggan. Perusahaan yang bergerak di bidang jasa telekomunikasi semakin bertambah dari tahun ke tahun mengingat kebutuhan telekomunikasi yang semakin banyak. Jumlah pengguna seluler di Indonesia hingga bulan Juni 2014 diperkirakan mencapai 180 juta pelanggan, atau mencapai sekitar 80 persen populasi penduduk. Menurut catatan ATSI (Asosiasi 
Telekomunikasi Seluler Indonesia), jumlah pengguna seluler di Indonesia hingga bulan Juni 2014 mencapai sekitar 59 juta lebih. Industri jasa telekomunikasi ini diperkirakan terus tumbuh, investasi terus meningkat menjadi sekitar US\$2 miliar per tahun, dengan jumlah BTS mencapai lebih 100.000 unit.

Perkembangan jasa telekomunikasi yang begitu pesat menyebabkan persaingan juga semakin ketat, tumpuan perusahaan untuk tetap mampu bertahan hidup adalah pelanggan yang loyal. Perusahaan harus jeli dalam melihat perubahan kebutuhan pelanggan, sehingga perusahaan dapat selalu memberikan pelayanan yang sesuai. Untuk itu, sebuah manajemen yang baik, harus mempunyai strategi organisasi yang tepat dan mampu melakukan yang terbaik untuk meningkatkan penjualan. Situasi ini memaksa setiap perusahaan untuk mempunyai strategi menarik pelanggan baru dengan tetap mempertahankan pelanggan lama. Salah satu alternatif yang digunakan adalah melalui penerapan Customer Relationship management, baik untuk mempertahankan pelanggan lama maupun mencari pelanggan baru.

Menurut Kotler (2008), Customer Relationship Management merupakan pendekatan bagi perusahaan untuk mengidentifikasikkan, melaksanakan, memperoleh, mempertahankan pelanggan melalui aktivitas manajemen data pelanggan. Menurut Francis Buttle (2004) tujuan utama yang ingin Customer Relationship Management (CRM) adalah untuk mengembangkan hubungan yang menguntungkan dengan pelanggan. Customer Relationship Management terdiri atas sub konsep dimensi yaitu teknologi, proses, orang dan pengetahuan.

PT. Indosat Tbk Cabang Bengkulu merupakan sebuah perusahaan yang bergerak dalam bidang jasa telekomunikasi. Produk yang ditawarkan antara lain adalah Im3, Mentari dan Matrix. Im3 dan Mentari tersebut merupakan produk PT. Indosat yang sudah lama dipasarkan, sedangkan produk Matrix relatif baru. Dalam mempertahankan pelanggannya PT.Indosat menggunakan program Telecall untuk melakukan hubungan dengan pelanggan. Telecall bertujuan untuk memberikan kemudahan kepada pelanggan dalam menyampaikan keluhannya jika terjadi ketidaklancaran berkomunikasi atau mengalami ganguan jaringan seperti menanyakan kondisi produk, menanyakan keluhan-keluhan serta menerima masukan dari pelanggan dengan mengumpulkan segala bentuk interaksi pelanggan baik itu lewat telepon, e-mail, hasil pembicaraan dengan staf pemasaran. Indosat adalah Perusahaan berbasis teknologi yang senantiasa berkembang dengan pesat. Indosat telah menyiapkan fondasi bisnis yang terencana dengan matang. Indosat selalu melayani pelanggan dengan baik, namun melihat persaingan yang semakin tajam maka pelayanan perlu ditingkatkan secara terus menerus. Salah satu bentuk pelayanan Indosat dengan implementasi sistem Customer Relationship Management (CRM).

Berdasarkan pada kondisi yang ada, perusahaan Indosat Tbk Bengkulu telah memberikan strategi bauran pemasaran yang mampu memberikan kepuasan kepada pelanggan. Pada gilirannya kepuasaan pelanggan dapat menciptakan kesetiaan dan loyalitas kepada perusahaan. Oleh karena itu, menarik untuk mengkaji atau menganalisis pengaruh Customer Relationship Management (CRM) pada loyalitas pelanggan perusahaan jasa PT. Indosat Tbk Bengkulu.

\section{Kerangka Analisis}

Kajian teoritis dan studi empiris terdahulu, Berikut kerangka model penelitian yang dianalisis dalam penelitian ini.

\begin{tabular}{|c|c|}
\hline $\begin{array}{c}\text { Customer Relationship Management } \\
\text { Dilihat dari } 4 \text { faktor }\end{array}$ & \\
\hline Teknologi $\left(\mathrm{X}_{1}\right)$ \\
\hline Orang $\left(\mathrm{X}_{2}\right)$ \\
\hline Proses $\left(\mathrm{X}_{3}\right)$ \\
\hline Pengetahuan $\left(\mathrm{X}_{4}\right)$ \\
\hline Loyalitas $(\mathrm{Y})$ \\
\hline
\end{tabular}

Sumber : Gordon 2002

Gambar 1. Kerangka Analisis

\section{METODE PENELITIAN}

Jenis penelitian yang digunakan adalah metode penelitian survey, yaitu suatu penelitian yang mengambil sampel populasi dan menggunakan kuesioner sebagai alat ukur data yang pokok. Data yang 
diperoleh dalam penelitian ini bersumber pada data primer yaitu data penelitian yang diperoleh secara langsung dari objek penelitian. Data diperoleh dari hasil penyebaran kuesioner. Metode penyebaran kuesioner digunakan untuk mengumpulkan data dari responden mengenai tanggapan responden terhadap variabel penelitian. Untuk sistem item pertanyaan diberi skor satu sampai lima. Populasi penelitian ini adalah konsumen Indosat Bengkulu. Ukuran sampel paling sedikit 50 responden dan disarankan ukuran sampel 100 responden, sehingga jumlah sampel yang digunakan oleh peneliti adalah sebanyak 100 responden.

Tabel 1. Uji Reliabilitas Variabel Penelitian

\begin{tabular}{|l|c|}
\hline \multicolumn{1}{|c|}{ Variabel Penelitian } & Koefisien Alpha Cronbach \\
\hline Teknologi & 0,634 \\
\hline Orang & 0,707 \\
\hline Proses & 0,667 \\
\hline Pengetahuan & 0,665 \\
\hline
\end{tabular}

Sumber : Hasil Penelitian 2014. Data diolah.

Berdasarkan Tabel diperoleh hasil bahwa nilai alpha cronbach yang dihasilkan masing- masing variabel penelitian berkisar antara 0,634-0,707 lebih besar dari 0,60. Dengan demikian dapat disimpulkan bahwa seluruh variabel penelitian adalah reliabel.

\section{Metode Analisis Data}

Teknik analisis data yang digunakan dalam menganalisa pengaruh variabel independen terhadap variabel dependen adalah analisis regresi berganda.Untuk mengetahui besarnya sumbangan variabel teknologi, orang, proses, pengetahuan terhadap loyalitas pelanggan maka digunakan analisis regresi berganda.

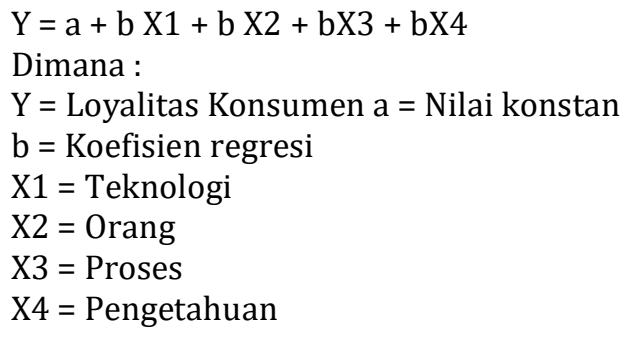

\section{HASIL DAN PEMBAHASAN Analisis Regresi}

Untuk melihat apakah Customer Relationship Management (CRM) berpengaruh terhadap loyalitas pelanggan dari 4 faktor yaitu teknologi, orang, proses dan pengetahuan digunakan pendekatan dari perhitungan komputer dengan menggunakan program SPSS.

Tabel 2. Coefficients ${ }^{\mathrm{a}}$

\begin{tabular}{|c|c|c|c|c|c|c|}
\hline \multirow{2}{*}{\multicolumn{2}{|c|}{ Model }} & \multicolumn{2}{|c|}{ Unstandardized Coefficients } & \multirow{2}{*}{$\begin{array}{c}\text { Standardized } \\
\text { Coefficients } \\
\text { Beta }\end{array}$} & \multirow[t]{2}{*}{$\mathrm{t}$} & \multirow[t]{2}{*}{ Sig. } \\
\hline & & B & Std. Error & & & \\
\hline \multirow{5}{*}{1} & (Constant) & 5.776 & 2.813 & & 2.054 & .043 \\
\hline & Teknologi_X1 & .085 & .072 & .110 & 1.773 & .224 \\
\hline & Orang_X2 & .030 & .067 & .043 & .447 & .656 \\
\hline & Proses_X3 & .159 & .084 & .180 & 1.885 & .062 \\
\hline & Pengetahuan X4 & .295 & .086 & .328 & 3.443 & .001 \\
\hline
\end{tabular}

a. Dependent Variable:_Y

Sumber : Hasil Penelitian 2014, Data diolah

Berdasarkan tabel 2 diatas, maka didapat persamaan garis linier sederhana dari persamaan umumnya:

$\mathrm{Y}=5,776+0,085 \mathrm{X} 1+0,030 \mathrm{X} 2+0,159 \mathrm{X} 3+0,295 \mathrm{X} 4$ 
Interprestasi hasil koefisien regresi pada persamaan diatas adalah :

1. Koefisien regresi variabel Teknologi (X1) terhadap loyalitas pelanggan pada PT.Indosat Tbk Cabang Bengkulu diperoleh $(\beta 1)=0,085$ dan $(t)=1,173$ artinya Teknologi berpengaruh terhadap loyalitas pelanggan sebesar 1,173.

2. Koefisien regresi variabel orang $\left(\mathrm{X}_{2}\right)$ terhadap loyalitas pelanggan pada PT.indosat Tbk Cabang Bengkulu diperoleh $\left(\beta_{2}\right)=0,030$ dan $(t)=0,447$ artinya orang berpengaruh terhadap loyalitas pelanggan sebesar 0,447 .

3. Koefisien regresi variabel proses $\left(\mathrm{X}_{3}\right)$ terhadap loyalitas pelanggan pada PT.Indosat Tbk Cabang Bengkulu diperoleh $\left(\beta_{3}\right)=0,159$ dan $(t)=1,885$ artinya proses berpengaruh terhadap loyalitas pelanggan sebesar 1,885 .

4. Koefisien regresi variabel pengetahuan (X4) terhadap loyalitas pelanggan pada PT.Indosat Tbk Cabang Bengkulu diperoleh $(\beta 4)=0,295$ dan $(t)=3,443$ artinya pengetahuan berpengaruh terhadap loyalitas pelanggan sebesar 3,443.

Dapat disimpulkan berdasarkan koefisien regresi variabel tingkat pengaruh yang tinggi dalam menciptakan loyalitas pelanggan yaitu pada variabel pengetahuan dengan nilai koefisien sebesar 0.295 dan di ikuti dengan variabel proses sebesar 0,159,variabel teknologi sebesar

0,085 serta yang terakhir pada variabel orang sebesar 0,030 .

Uji t

Pengujian uji t dilakukan untuk mengetahui masing-masing variabel bebas secara parsial terhadap variabel terikat loyalitas pelanggan. Oleh karena itu, tujuan penelitian adalah untuk membuktikan ada tidaknya pengaruh variabel independen pada penelitian ini yang meliputi teknologi, orang, proses, pengetahuan secara parsial terhadap variabel dependen. Berikut penjelasan pengujian masing-masing variabel secara parsial.

\section{Pengujian Variabel teknologi}

Dari hasil pengolahan data yang disajikan terlihat bahwa variabel teknologi tidak memiliki pengaruh yang positif dan signifikan yang tandai dengan nilai thitung sebesar 1,173 dan lebih kecil dari ttabel yaitu sebesar 1,984 pada tingkat kepercayaan atau alpha 5\%. Hal ini juga dibuktikan dengan nilai signifikan $(0,244)$ dari variabel ini lebih besar dari nilai alpha yaitu 0,05. Dengan demikian variabel teknologi secara parsial tidak memiliki pengaruh yang signifikan terhadap pembentukan loyalitas penggunan produk PT. Indosat Tbk Bengkulu.

\section{Pengujian Variabel Orang}

Dari hasil pengolahan data yang disajikan terlihat bahwa variabel orang tidak memiliki pengaruh yang positif dan signifikan yang tandai dengan nilai thitung sebesar 0,447 dan lebih kecil dari tabel yaitu sebesar 1,984 pada tingkat kepercayaan atau alpha 5\%. Hal ini juga dibuktikan dengan nilai signifikan ( 0,656) dari variabel ini lebih besar dari nilai alpha yaitu 0,05. Dengan demikian variabel Orang secara parsial tidak memiliki pengaruh yang signifikan terhadap pembentukan loyalitas penggunan produk PT. Indosat Tbk Bengkulu.

\section{Pengujian Variabel Proses}

Dari hasil pengolahan data yang disajikan terlihat bahwa variabel proses tidak memiliki pengaruh yang positif dan signifikan yang tandai dengan nilai thitung sebesar 1,885 dan lebih kecil dari tabel yaitu sebesar 1,984 pada tingkat kepercayaan atau alpha 5\%. Hal ini juga dibuktikan dengan nilai signifikan $(0,062)$ dari variabel ini lebih besar dari nilai alpha yaitu 0,05 . Dengan demikian variabel proses secara parsial tidak memiliki pengaruh yang signifikan terhadap pembentukan loyalitas penggunan produk PT. Indosat Tbk Bengkulu.

\section{Pengujian Variabel Pengetahuan}

Dari hasil pengolahan data yang disajikan terlihat bahwa variabel pengetahuan memiliki pengaruh yang positif dan signifikan yang tandai dengan nilai thitung sebesar 3,443 dan lebih besar dari ttabel 
yaitu sebesar 1,984 pada tingkat kepercayaan atau alpha 5\%. Hal ini juga dibuktikan dengan nilai signifikan ( 0,001) dari variabel ini lebih kecil dari 0,05. Dengan demikian variabel pengatahuan secara parsial memiliki pengaruh yang signifikan terhadap pembentukan loyalitas penggunan produk PT. Indosat Tbk Bengkulu.

\section{Uji F}

Uji F pada dasarnya menunjukan apakah semua variabel independen yang dimasukan dalam model mempunyai pengaruh secara bersama-sama terhadap variabel dependen. Dalam penelitian pengujian hipotesis dimasukan untuk mengukur besarnya pengaruh variabel independen yang meliputi teknologi, orang, proses, pengetahuan secara bersama-sama terhadap variabel dependen, yaitu loyalitas pelanggan. Berdasarkan hasil pengujian Hipotesis Uji $\mathrm{F}$ dapat diketahui Fhitung untuk variabel Teknologi, Orang, Proses dan Pengetahuan adalah 5,405 dengan nilai signifikan sebesar 0,001. Ini berarti bahwa Teknologi, Orang, Proses dan Pengetahuan secara simultan berpengaruh positif terhadap loyalitas pelanggan.

Tabel 3. ANOVA ${ }^{\mathrm{b}}$

\begin{tabular}{|cc|c|c|c|c|c|}
\hline & Model & $\begin{array}{c}\text { Sum of } \\
\text { Squares }\end{array}$ & df & Mean Square & F & Sig. \\
\hline \multirow{2}{*}{1} & Regression & 96.731 & 4 & 24.183 & 5.405 &, $001^{\mathrm{a}}$ \\
& Residual & 425.059 & 95 & 4.474 & & \\
\hline & Total & 521.790 & 99 & & & \\
\hline
\end{tabular}

a. Predictors: (Constant), X4, X3, X1, X2 b. Dependent Variable: $\mathrm{y}$

Sumber : Hasil Penelitian 2014, Data di olah.

Hasil ini memperlihatkan bahwa nilai signifikan uji ini jauh lebih kecil dari nilai alpha $(0,05)$ yang ditetapkan sebagai batas toleransi, dengan demikian nilai Fhitung yang diperoleh adalah signifikan. Oleh karena itu, dapat disimpulkan bahwa variabel teknologi, oran, proses, dan pengetahuan secara simultan atau bersama-sama berpengaruh terhadap pembentukan loyalitas produk indosat bengkulu. Dengan demikian ( $\mathbf{H}_{\mathbf{O}}$ ) yang diuji dalam penelitian ini di tolak dan menerima $\left(\mathbf{H}_{\mathbf{a}}\right)$.

\section{Pengaruh Teknologi Terhadap Loyalitas Pelanggan}

Berdasarkan analisa regresi berganda diperoleh hasil bahwa variabel teknologi tidak memiliki pengaruh yang positif dan signifikan terhadap loyalitas pelanggan. Berdasarkan nilai hubungan antar variabel ini, hasil analisa regresi diperoleh koefisien regresi sebesar 0,085. Hal ini memperlihatkan bahwa secara parsial variabel teknologi memiliki pengaruh sebesar 0,085 terhadap pembentukan loyalitas pelanggan.

Teknologi pada PT. Indosat tidak berpengaruh dalam meningkatkan loyalitas karena sekarang ini teknologi yang lebih digunakan hanya sebagai promosi yang terkadang pada kenyataannya promosi tersebut baik itu melalui media cetak ataupun elektronik saat ini sudah tidak terlalu diperhatikan lagi oleh kunsumen apalagi dapat kita lihat bahwa ditinjau dari tanggapan responden atas karakteristik reponden mayoritas pelanggan Indosat berumur 21-30 tahun yang merupakan usia produktif dengan mayoritas pelajar dan mahasiswa yang seringkali menganggap kegunaan promosi melalui teknologi baik media cetak maupun elektronik tidak terlalu penting dan bahkan tidak dihiraukan karena dianggap hanya mengganggu, sehingga indikator tersebut kurang menjadi faktor menarik pelanggan untuk menjadi loyal.

\section{Pengaruh Orang Terhadap Loyalitas Pelanggan}

Ditinjau dari keterkaiatan variabel Orang dan loyalitas pelanggan ditemukan bahwa kedua variabel ini tidak memiliki pengaruh yang positif dan signifikan. Besaran nilai koefisien akan pengaruh variabel orang atau sumber daya manusia terhadap loyalitas pelanggan diperoleh 0.030. Yang berarti sumber daya manusia yang ada pada PT.Indosat Tbk Bengkulu masih kurang dalam melayani dan menangani pelanggan.

Orang merupakan instrument penting yang akan membuat pelanggan berperilaku positif seperti, perilaku untuk mempromosikan, mereferensikan produk perusahaan kepada pihak lain (Dibb dan Meadows 2004). Pengelolaan orang atau karyawan pada dasarnya akan memiliki pengaruh yang besar bagi berbagai aspek dalam perusahaan yang pada akhirnya akan bermuara pada loyalitas pelanggan 
hal ini penting untuk diperhatian PT.Indosat agar kualitas orang atau sumber daya manusia dapat selalu ditingkatkan.

\section{Pengaruh Proses Terhadap Loyalitas Pelanggan}

Hasil analisis yang dilakukan atas data yang telah dihimpun melalui pengumpulan data

yang dilakukan diperoleh bahwa proses atas ketersedian pelayanan tidak memiliki pengaruh yang positif dan signifikan terhadap pembentukan loyalitas pelanggan Indosat di Bengkulu. Hal ini ditunjukkan nilai koefisien regresi sebesar 0,159. Dari hasil penelitian ini terlihat bahwa pelanggan belum puas atas proses layanan dan ketersediaan pelayanan yang ada pada PT.Indosat Tbk Bengkulu. Kondisi ini memperlihatkan bahwa perlu dilakukan perbaikan yang lebih maksimal dalam membangun kebanggan pelanggan akan proses di Indosat. Proses perusahaan untuk mengakses dan berinteraksi dengan pelanggan mereka dan saling memuaskan (Gordon 2002).

\section{Pengaruh Pengetahuan Terhadap Loyalitas Pelanggan}

Hasil analisis yang dilakukan atas data yang telah dihimpun melalui pengumpulan data yang dilakukan diperoleh bahwa pengetahuan memiliki pengaruh yang positif dan signifikan terhadap pembentukan loyalitas pelanggan Indosat di Bengkulu. Hal ini ditunjukkan nilai koefisien regresi sebesar 0,295 . Selain itu juga ditinjau dari tanggapan responden atas variabel pengetahuan, hasil olah data dan dilihat dari distribusi frekuensi atas indikator dan dimensi penelitian diperoleh nilai respon secara rata-rata total 3.68. Nilai respon ini berada pada katagori "Tinggi" (berada pada interval kelas 3,404,19). Hal ini menggambarkan bahwa PT.Indosat secara keseluruhan telah memperoleh pengetahuan yang tinggi mengenai pelanggan baik pengetahuan tentang data pelanggan maupun kebutuhan dan harapan pelanggan yang merupakan hal yang penting untuk diperhatian oleh perusahaan dalam rangka meningkatkan loyalitas pelanggan. Dalam customer relationship management database pelanggan yang menjadi senjata utama pelayanan dalam penyediaan informasi (Sinaga, 2006). Dari hasil ini terlihat bahwa pengetahuan perusahaan yang kuat tentang informasi rinci masing-masing pelanggannya, baik itu pengetahuan mengenai data pelanggan sampai keseluruhan kinerja yang sesuai dengan keinginan pelanggan, mereka akan lebih merasa diperhatikan dan merasa puas maka konsumen menjadi loyal. Penelitian ini mendukung pendapat Gordon (2002), bahwa pengetahuan merupakan pendekatan yang di gunakan perusahaan untuk menambah nilai kepada pelangan melalui data sehingga dapat memperdalam hubungan.

\section{Kesimpulan}

1. Pengaruh pengetahuan dalam meningkatkan loyalitas pelanggan PT.Indosat Tbk Bengkulu adalah positif dan signifikan. Hal ini dibuktikan oleh nilai uji t dan nilai signifikan $(0,001)$ dari variabel ini lebih kecil dari 0,005. Besaran nilai koefisien hubungan variabel ini adalah sebesar 0,295.

2. Hasil analisis regresi menunjukan teknologi, orang dan proses tidak memiliki pengaruh yang positif dan signifikan dalam meningkatkan loyalitas pelanggan PT. Indosat Tbk Bengkulu. Hal ini juga dibuktikan dengan hasil pengolahan data yang disajikan terlihat bahwa variabel teknologi, orang dan proses tidak memiliki pengaruh yang positif dan signifikan yang tandai dengan nilai thitung sebesar teknologi $(1,173)$, orang $(0,447)$ dan proses $(0,062)$ lebih kecil dari ttabel yaitu sebesar 1,984 pada tingkat kepercayaan atau alpha $5 \%$.

3. Berdasarkan hasil uji simultan (uji F) terbukti bahwa secara simultan variabel teknologi, orang, proses dan pengetahuan memiliki pengaruh yang sigifikan terhadap pembentukan loyalitas pelanggan. Hal ini dibuktikan oleh nilai uji F dengan nilai signifikan 0,001 yang berada jauh lebih kecil dari nilai alpha $(0.005)$

\section{Saran}

Untuk mempertahankan loyalitas pelanggan yang menjadi tujuan dari Customer Relationship Management (CRM), PT.Indosat Tbk Cabang Bengkulu harus mampu meningkatkan hubungan jangka panjang yang kuat dengan pelanggan. Upaya yang dapat dilakukan PT. Indosat untuk mempertahankan loyalitas adalah:

- Dengan lebih meningkatkan kualitas teknologi terutama pada penyediaan peralatan hubungan dengan pelanggan melalui email yang masih rendah dengan cara mengumpulkan informasi-informasi yang lebih rinci tentang data pelanggan khususnya pada email.

- Meningkatkan pelayanannya terutama dibagian call center pada jam-jam sibuk agar tercipta keakraban antara karyawan dengan pelanggan agar tercipta intensitas komunikasi yang lebih lama dan tingkat profesionalisme karyawan yang tinggi. 
- Indosat harus lebih meningkatkan kualitas proses terhadap pelayanan melalui email dan hubungan pelanggan dengan membuat kartu member khusus untuk pelanggan serta dengan cara membentuk hubungan yang proaktive dengan memelihara hubungan pelanggan untuk memberikan informasi dan menampung saran dan keluhan mengenai perkembangan produk dan layanan perusahaan dalam rangka membangun hubungan berkelanjutan dengan pelanggan yang baik.

- Meningkatkan kualitas pengetahuan terutama pada tingkat pengetahuan terhadap hari-hari penting bagi pelanggan dan tingkat keterlibatan pelanggan dengan cara Indosat mengadakan acaraacara games yang lebih melibatkan pelanggan dan mengumpulkan informasi-informasi yang lebih rinci mengenai data pelanggan terhadap hari-hari penting bagi karyawan karena dengan hal tersebut menunjukan perhatian perusahaan terhadap pelanggannya yang akan mengarah pada kepuasaan pelanggan.

\section{DAFTAR PUSTAKA}

Alfansi, Lizar. 2010. Financial Services Marketing. Jakarta. Salemba Empat.

Body dan Limayem. 2004. The Impact of Customer Relationship Management. University of North Dakota.

Dick, A. S., \& Basu, K. (1994). Customer loyalty: Toward an integrated conceptual framework. Journal of the Academy of Marketing Science.

Dibb, Sally., and, Maureen Meadows (2004), " Relationship marketing and CRM: a financial service case study ", Journal of Strategy Marketing, Vol. 12 p. 11-125

Fatmah dan Wasto. 2011 . Customer Relationship. Journal Manajemen Usahawan Indonesia. Vol. 41, No. 1.

Ferdinand. 2006. Metodologi Penelitian Manajemen. Edisi keenam. Semarang.

Buttle, francis. (2004). Customer Relationship Management (Manajemen Hubungan Pelanggan) Concept And Tools. Malang: Banyumedia. Griffin, Jill. (2003). Customer loyalty. Jakarta: Erlangga.

Gordon, Ian. (2002). Best Practices: Customer Relationship Management. Ivey Business Journal.

Handoko, T. Hani. 1999. Manajemen. Edisi 2. Yogyakarta BPFE.

Hair,J.F., Anderson, R.E., Tatham, R.L., and black W.C. (1998). Multivariate

Data Analysis, 5th ed., Upper Sadlle River, New Jersey: Prentice Hall. Kotler, Philip. 2002. Manajemen Pemasaran. Edisi Kesepuluh. Diterjemahkan oleh Benyamin Molan. Jilid 1. Jakarta : Indeks.

Kotler, Philip. 2003. Manajemen Pemasaran. Edisi 3. Jakarta : PT. Indeks.

Kotler dan Armstrong. 2008. Prinsip-prinsip pemasaran. Edisi kedua belas. Diterjemahkan oleh Benyamin molan. Jilid 1. Jakarta. Indeks.

Kotler, Keller. 2009. Marketing Manajemen. Edisi kedua belas. Diterjemahkan oleh Benyamin molan. Jilid 1. Jakarta. Indeks.

Kurtz, L, D., Clow, E, K. (1998). Service Marketing. Prentice-Hall. New Jersey.

Saputri, 2010. Pencapaian Tujuan Perusahaan dengan Customer Relationship Management. Binus University.

Sekaran, Uma. 2003. Research Methods For Business. Fourth Edition, John Wiley \& Sons. United States of America.

Siahaan, 2008. Customer Relationship Management (CRM). Journal Studi Perpustakaan dan Informasi. Vol.4, No. 2.

Sinaga, Sabam. (2006). "Pengaruh Customer Relationship Management terhadap Loyalitas Konsumen". Bandung.

Sopiah dan Sangadji, 2010. Metodologi Penelitian.Yogyakarta. Stoner, AF. James.1996. Manajemen. Jakarta. Erlangga.

Swastha, Basu. 1996. Azaz-azaz marketing. Yogyakarta: Liberty.

Turban, Efraim.(2004). Electronic Commerce: A Managerial Perspective. Pearson

Education, New Jersey.

Yahya, Yohannes. 2009. Customer Relationship Management.

http://terapibisnis.com/artikel-tb/85-implementasicustomerrelationship management-crm dalammeningkatkan-loyalitaspelanggan.

http://blog.uad.ac.id/sulisworo/2009/04/24/customer-relationship-management/

http://id.wikipedia.org/wiki/Manajemen_hubungan_pelanggan

http://id.wikipedia.org/wiki/Telekomunikasi_seluler_di_Indonesia 